\title{
INSTALATION FOR INDUCTION HEATING FOR TESTING THERMO SENSORS
}

\author{
Peter Ivanov Tomchev, Nikolay Hristov Nenov, \\ Rayna Georgieva Ivanova \\ Technical University - Gabrovo \\ 4, H. Dimitar St., Gabrovo, 5300, Bulgaria \\ Ph.: +(359)66827481, e-mail: nenovtugabrovo@gmail.com
}

\begin{abstract}
With constant development and improvement of management systems in modern technological processes, in cars, in production lines and machinery and other fields are increasingly entering the use of different sensors. These sensors are tested on special test simulators, simulating the conditions for a long time close to their work. Often the temperature is in the range of $700-900^{\circ} \mathrm{C}$. To achieve these temperatures, most environmentally safe and effective heating of the sensors can be achieved by induction heating of housing them. The object of this report is installation for induction heating system as part of the simulator to test the vibration and temperature thermal sensors.
\end{abstract}

Keywords: temperature sensor, induction heating, rectifier, width switching regulator, inverter.

\section{Introduction}

Some of them work under harsh conditions such as high mechanical vibrations and high temperatures. These are mainly thermal sensors used in technological processes of heat in cars and others. Figure 1 shows a picture of some of the widespread thermal sensors car.



Fig. 1. Picture of some of the widespread thermal sensors car

\section{Exibition}

For specific application one of the most important requirements for the installation of induction heating is a broad range of regulatory power to set the temperature sensor on a particular algorithm or temperature changes widely in random. 
The most used ways of power adjustment are:

- Adjustable Rectifier with a phase adjustment;

- Diode rectifier with DC pulse-width regulator;

- Frequency control of inverter with a consistent flickering circle.

Current requirements for mains ecology of a more sophisticated filter restricts the use of rectifier with phase control. Important factor is the power plant. Small dimensions and mass of the sensor and its housing need to be determined by low active power - $2-3 \mathrm{~kW}$. On the other hand, to provide the necessary amplitude of mechanical vibration sensors in the inductor, it is oblong or rectangular shape and size much larger than the body of the sensor. In most cases, housing is non-magnetic metal, usually chrome-nickel alloys. Course received a very large air gap between the work piece and inductor defines low $\cos \varphi$, therefore more reactive power and complete the circle. This fact determines the use of coherent flickering circle as ineffective. On the other hand switching regulator power $2-3 \mathrm{~kW}$ is the standard converter. For those reasons, he was elected DC / DC switching regulator power. Simplified block diagram of induction heating device is shown in Figure 2.

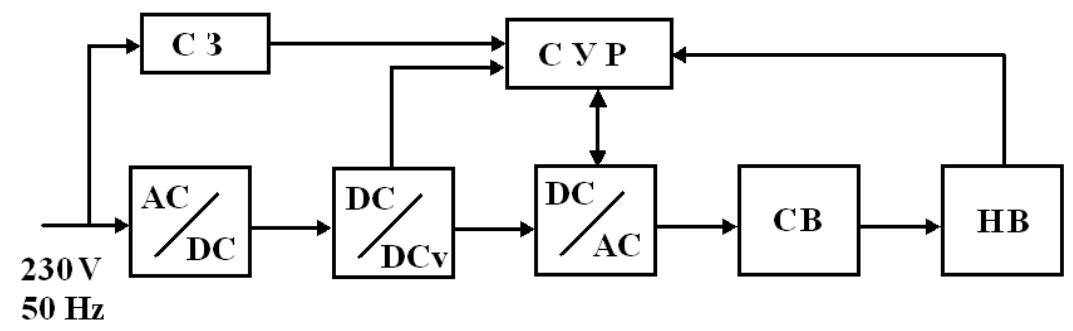

\section{Fig. 2. Simplified block diagram of induction heating device}

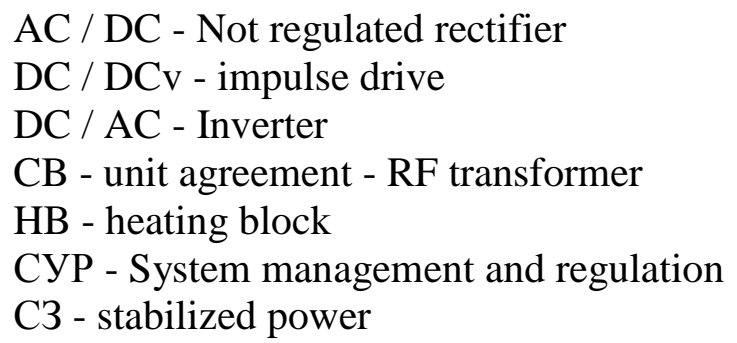

Adjustable DC power supply is realized by a diode bridge rectifier with capacitive filter and a switching regulator circuit of one-key buck converter.

Its principal scheme is shown in Figure 3.

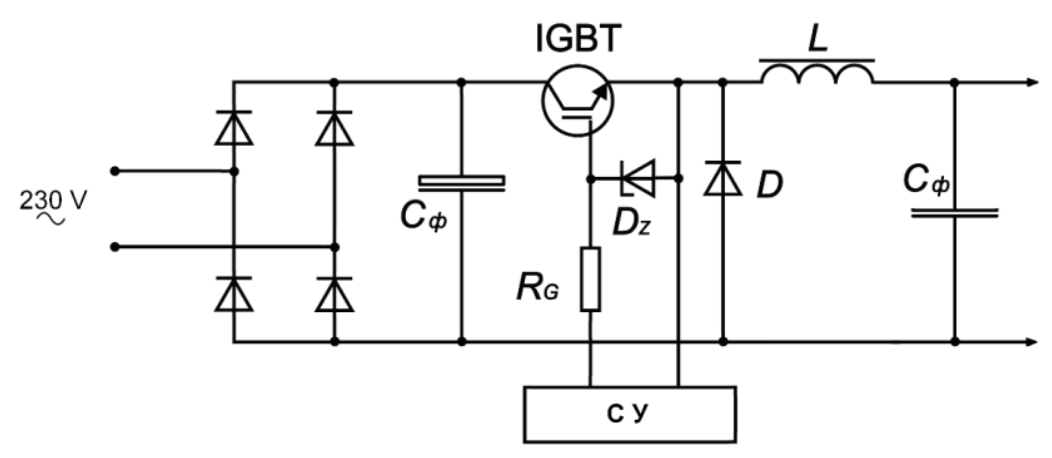

Fig. 3. Schematic of a buck converter key 
The output voltage Uo depends on the duration of operation of transistors and diodes (impulse control), therefore the coefficient of filling of the control signal of the transistor.

$$
\begin{aligned}
& \gamma=\mathrm{t}_{\mathrm{ON}} / \mathrm{T} \\
& \mathrm{t}_{\mathrm{ON}} \text { - duration of the control pulse; } \\
& \mathrm{T} \text { - period of control signal. }
\end{aligned}
$$

The adjustment range of the output voltage is 150 to $300 \mathrm{~V}$, and regulation is smooth. Tension can be set manually - by potentiometer or automatically - by request of the computer. In principle of operation of the pulse regulator has no specific features deriving from its particular application and therefore may not be his special attention.

Greater interest is the DC / AC converter. The main criteria for selecting circuit and transistors are reduced to power and operating frequency. In determining the optimal operating frequency has two conflicting characteristics. On the one hand small dimensions and thickness of the hull of the sensor requires a high frequency. On the other hand large air gap and non-magnetic metals require operation at lower frequencies. It is experimentally established that good technological effect is obtained at operating frequencies $65-75 \mathrm{kHz}$. For these frequencies and capacities up to $2-3 \mathrm{~kW}$ can be used all the schemes of resonant inverters. For less Transfer to and effective use of the matching transformer is selected halfbridge scheme resonant inverter. Pulse power source allows power regulation and implementation of the necessary equipment for such protections. This reduces the system requirements for the management of the inverter to control the formation of pulses with the required frequency. For these requirements the most inexpensive, is simple and reliable system management oscillator principle. Figure 4 shows the scheme of half-bridge oscillator resonant inverter.

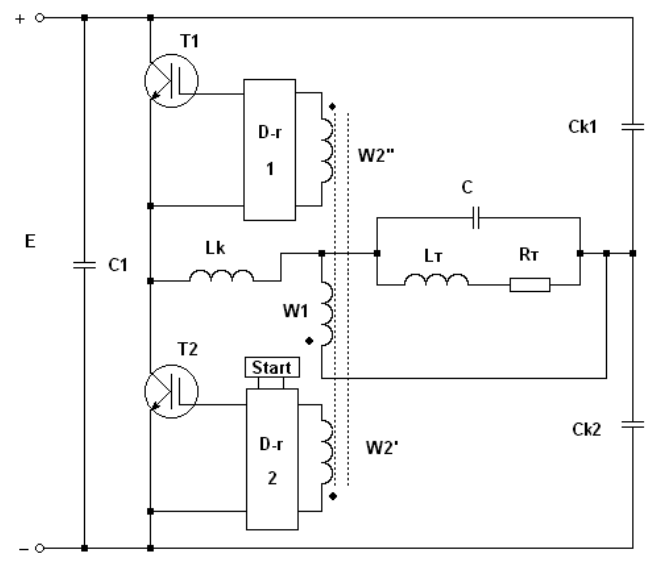

\section{Fig. 4. Scheme of the oscillator resonant half bridge inverter}

In principle of operation of the power scheme has no specific features. Interest is in the case of an oscillator control. The ruling scheme is limited to low-powered transformer feedback amplifiers to form governing impulses - drivers and starting device. The principle of operation is illustrated by timing diagram shown in Figure 5.

Feedback transformer has a primary coil connected in parallel to the freight flickering circle and two opposing same coiled coil secondary connected to the drivers. (Figure 4).

In the initial commissioning of the converter, starter drive (Start) produces a single impulse control Up to transistor T2. Pulse duration is less than half period of the highest possible operating frequency (Fig. 5). Transistor T2 is turned on, is brought energy to the load range and occurs oscillate process. The two secondary windings W2', W2' transformer feedback appears sinusoidal signal phase shift of $180^{\circ}$. Under terms of cells marked in Fig.4 shows that W2" is in phase with W1. Therefore, as Driver 2 is brought positive half-shaft and he formed 
a steering impulse $\mathrm{U}_{\mathrm{GE} 2}$ for $\mathrm{T} 2$ (Fig. 5). To a driver shall be filed negative half-shaft of sine wave of W2' and T1 is blocked. Once the voltage range of freight and W1 changed its polarity to Driver 2 is brought negative half-shaft and worked transistor T2 is turned off. At the same time to the driver 1 is passed positive half-shaft and T1 is switched on. In the next period the process is repeated, but without starting pulse (Fig. 5).

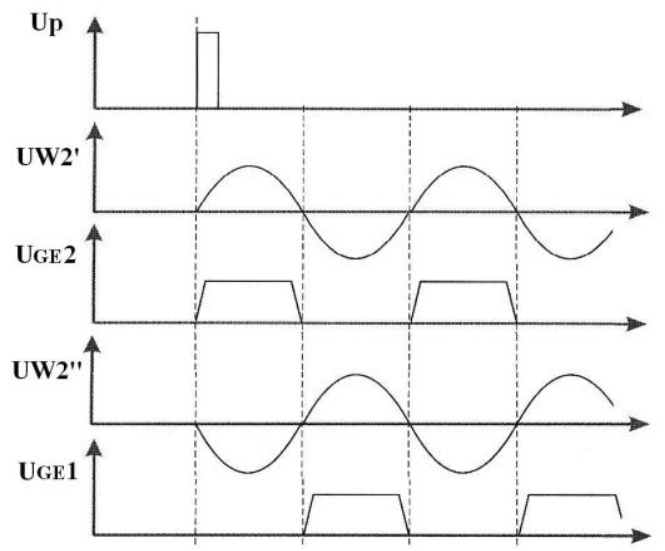

Fig. 5. Timeline of the control circuit

Management of transistors by a signal from the load range, with almost no logical processing provides self frequency of the inverter with the load. This self-ordination is both dynamic mode (during heating) and on initial start-up. That is what ensures reliable operation at relatively steady speeds of transistors in the entire process.

Examined for induction heating device for testing thermal sensors is constructed and operates in real terms.

To illustrate the mode of the inverter of Figure 6 shows oscillograms of the collector-emitter voltage of transistor $\mathrm{T} 2$ and the current in the diagonal of the inverter (during the two transistors).

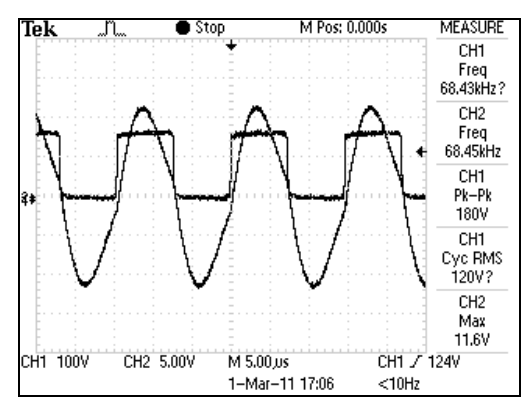

a)

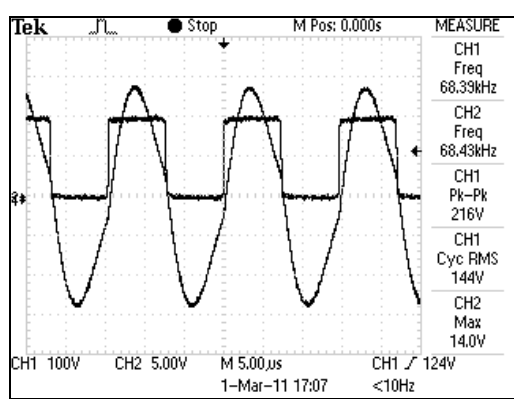

b)

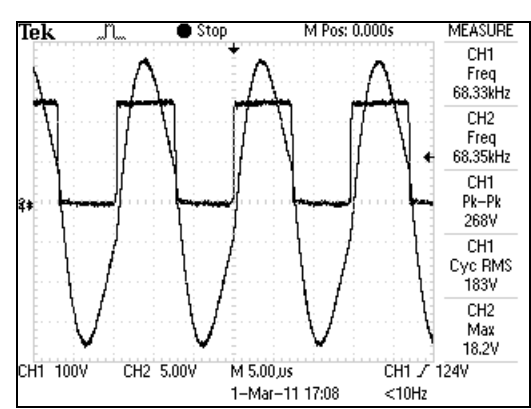

c)

Fig. 6. Oscillograms of the collector-emitter voltage of transistor $\mathbf{T} 2$ and the current in the diagonal of the inverter

It is seen that switching transistor is at almost zero current, so there are no voltage peaks $\mathrm{U}_{\mathrm{CE}}$. Oscillograms were photographed in a different assignment of pulse DC source. In Figure 6a) is at minimum voltage $\mathrm{Uo}=150 \mathrm{~V}, 6 \mathrm{~b})-$ at $250 \mathrm{~V}$, and $6 \mathrm{c}$ ) - intermediate voltage $200 \mathrm{~V}$. These figures confirm the strain of $\mathrm{U}_{\mathrm{CE}}$ blocked transistor. It also includes increases in the current diagonal under increasing DC. 


\section{Conclusion}

The realized system for induction heating in testing thermal sensors is shown in Figure 7. For easy installation in a constructive attitude, the loading range is exported in a separate box with a length of connecting wires $2.5 \mathrm{~m}$.



Fig. 7. Arrangements for induction heating for testing heat detectors

The device shows very good features in real working conditions as part of the tester thermal sensors vibration and temperature.

\section{References}

1. P. T. Ivanov, R. G. Ivanova, Dedicated low-power sources for induction heating, The ninth scientific and applied science conference with International Participation ELECTRONICS ET'2000, 20-22 September 2000, Sozopol, Vol 4, p.76-80.

2. P. T. Ivanov, Asymmetrical transistor oscillator inverter for induction heating, The eleventh international scientific and applied science conference ELECTRONICS ET'2002, 25-27 September 2002, Sozopol, Vol 4, p.250-255.

3. Todorov T., ND Madjarov, D.T. Alexiev, P.T. Ivanov, autonomous inverters, Gabrovo, 1996

4. P. S. Ivanov, T. Todorov, R., Transistor converters for induction heating in the MHz frequency range with self-excitation, E Magazine, Vol. 7-8, 2004, p.10-15. 